\title{
BMJ Open Antibiotic use in children with asthma: cohort study in UK and Dutch primary care databases
}

\author{
Esmé J Baan, ${ }^{1}$ Hettie M Janssens, ${ }^{2}$ Tine Kerckaert, ${ }^{3}$ Patrick J E Bindels, ${ }^{4}$ \\ Johan C de Jongste, ${ }^{2}$ Miriam C J M Sturkenboom, ${ }^{5}$ Katia M C Verhamme ${ }^{1,3,6}$
}

To cite: Baan EJ, Janssens HM, Kerckaert T, et al. Antibiotic use in children with asthma: cohort study in UK and Dutch primary care databases. BMJ Open 2018;8:e022979. doi:10.1136/ bmjopen-2018-022979

- Prepublication history and additional material for this paper are available online. To view these files, please visit the journal online (http://dx.doi. org/10.1136/bmjopen-2018022979).

Received 27 March 2018 Revised 23 October 2018 Accepted 25 October 2018
Check for updates

(C) Author(s) (or their employer(s)) 2018. Re-use permitted under CC BY-NC. No commercial re-use. See rights and permissions. Published by BMJ.

For numbered affiliations see end of article.

Correspondence to

Esmé J Baan;

e.baan@erasmusmc.nl

\section{ABSTRACT}

Objectives To compare the rate, indications and type of antibiotic prescriptions in children with and without asthma.

Design A retrospective cohort study.

Setting Two population-based primary care databases: Integrated Primary Care Information database (IPCl; the Netherlands) and The Health Improvement Network (THIN; the UK).

Participants Children aged 5-18 years were included from January 2000 to December 2014. A child was categorised as having asthma if there were $\geq 2$ prescriptions of respiratory drugs in the year following a code for asthma. Children were labelled as non-asthmatic if no asthma code was recorded in the patient file.

Main outcome measures Rate of antibiotic prescriptions, related indications and type of antibiotic drugs.

Results The cohorts in IPCl and THIN consisted of 946143 and 7241271 person years (PY), respectively. In both cohorts, antibiotic use was significantly higher in asthmatic children (IPCI: 197vs126 users/1000 PY, THIN: 374vs250 users/1000 PY). In children with asthma, part of antibiotic prescriptions were for an asthma exacerbation only (IPCl: $14 \%$, THIN: $4 \%$ ) and prescriptions were more often due to lower respiratory tract infections then in non-asthmatic children (IPCI: 18\%vs13\%, THIN: 21\%vs12\%). Drug type and quality indicators depended more on age, gender and database than on asthma status.

Conclusions Use of antibiotics was higher in asthmatic children compared with non-asthmatic children. This was mostly due to diseases for which antibiotics are normally not indicated according to guidelines. Further awareness among physicians and patients is needed to minimise antibiotic overuse and limit antibiotic resistance.

\section{INTRODUCTION}

Antibiotic resistance is one of the biggest threats to global health today, as recently stated by the WHO. ${ }^{1}$ Antibiotic resistance leads to higher medical costs, prolonged hospital stays and increased mortality. ${ }^{2}$ The world urgently needs to change the way it prescribes and uses antibiotics. The Netherlands has long been recognised as a role model in the restricted use of antibiotics. For example, due to restricted antibiotic use,

\section{Strengths and limitations of this study}

This study investigates antibiotic prescriptions in two large population-based databases.

- A major strength of this study is that the use of databases from different countries surpasses local prescription patterns.

- Because of the design of the study, misclassification of indications is possible.

- Antibiotic use depends on country, sex and gender; therefore, analyses were stratified.

methicillin-resistant Staphylococcus aureus rates are much lower in the Netherlands than in surrounding countries. ${ }^{34}$ Insights in antibiotic use for different patient groups and in different countries may help to develop best practices for optimal antibiotic use.

Studies indicate that children with asthma receive more antibiotics than children without asthma. ${ }^{5}{ }^{6}$ However, national and international guidelines clearly state that antibiotics are not indicated for an asthma exacerbation. $^{7-9}$ Respiratory infections may trigger an asthma exacerbation, but these are mostly viral infections. ${ }^{7}$ Insight in prescription patterns is a first step in detecting possible overuse and to initiate steps in reducing antibiotic use. Not only the prescription rate influences resistance patterns, also the type of antibiotic is important. Indeed, it is well known that broad spectrum antibiotics increase the risk of resistance more than narrow spectrum antibiotics. ${ }^{10}$

The aim of this study was to investigate differences in antibiotic prescriptions rates, type of antibiotic being prescribed and related indications in children with and without asthma in a primary care setting in different countries. In addition, we studied changes over time and associated quality indicators (QIs). 


\section{PATIENTS AND METHODS}

\section{Setting}

A retrospective, population-based cohort study was conducted using data from two primary care databases: the Integrated Primary Care Information database (IPCI) from the Netherlands and The Health Improvement Network (THIN) from the UK. Both databases contain detailed information on drug prescription, diagnoses and co morbidities. Detailed descriptions of these databases have been published elsewhere. ${ }^{11-13}$

\section{Patient and public involvement}

No patients and or public were involved in this study.

\section{Study population}

The study population comprised all children aged 5-18 years, with at least 1 year of valid database history and having at least 1 day of follow-up during the study period (from 1 January 2000 to 31st December 2014). Within this study population, we identified a cohort of children with asthma and a cohort of children without asthma. A child was diagnosed as having asthma if there were at least two prescriptions of respiratory drugs in the year following a code for asthma. These drugs consisted of bronchodilators, inhaled corticosteroids, leukotriene receptor antagonist or xanthines (Anatomical Therapeutic Chemical Classification System (ATC) code R03; British National Formulary (BNF) codes 3.1.1-3.1.4, 3.2, 3.3). If a patient was not diagnosed with a code for asthma, this child was labelled as non-asthmatic. Children with a diagnose code of asthma and less than two prescriptions of asthma drugs were excluded from analyses because of potential misclassification

\section{Exposure}

All antibiotic $(\mathrm{AB})$ prescriptions during the study period were identified from the patient files by an automated search on antibiotic drug codes (ATC code J01 for IPCI and BNF code 5.1 for THIN). To enable comparison between countries, BNF codes were mapped to the corresponding ATC codes.

\section{Indications}

To assess the underlying indications, the main indication code (Read codes in the THIN database and ICPC codes in the IPCI database) linked to the prescription was used. Only if no indication code of an infection was linked to the prescription, diagnostic codes entered in the patient's file on the same date as the antibiotic prescription were also considered as indication of use. Indications were divided into the following categories: upper respiratory tract infections (URTIs), skin infections (skin), urinary tract infections (UTI), asthma exacerbation (asthma), lower respiratory tract infections (LRTIs) and a combination of URTI and LRTI in case a patient had codes for both. Other indications were categorised as 'other', and since there were not many prescriptions with multiple indications, we categorised those as 'other' as well. As we were especially interested in LRTI, we categorised subtypes of LRTI's into 'bronchitis', 'pneumonia', 'combination of asthma exacerbation and bronchitis', 'influenza', 'tracheitis', 'unspecified' (if no further categorisation was possible) and 'other' (other LRTI or combinations of the previous). Tables with all indication codes and corresponding categories are available in online supplementary file 1 .

\section{Quality indicators}

To investigate differences in quality of antibiotic prescriptions in children with and without asthma, QIs were calculated as proposed by the European Surveillance of Antimicrobial Consumption and as described in literature. ${ }^{14}$ First, the types of antibiotics that covered $90 \%$ of $\mathrm{AB}$ prescriptions (drug utilisation 90\%) were assessed. ${ }^{15-17}$ Second, the ratio between broad-spectrum and narrow-spectrum antibiotics $(\mathrm{B} / \mathrm{N}$ ratio) was calculated. Two additional QIs that are specific for outpatient paediatric use were also investigated namely the amoxicillin index (AI, the number of amoxicillin prescriptions as percentage of total antibiotic prescriptions) and the ratio between amoxicillin and broad-spectrum antibiotics prescriptions (A/B ratio). Although amoxicillin is classified as an intermediate-spectrum antibiotic and therefore not in the $\mathrm{B} / \mathrm{N}$ ratio, it is considered the antibiotic of first choice for a large part of paediatric indications. ${ }^{81819} \mathrm{~A}$ high $\mathrm{AI}$ and $\mathrm{A} / \mathrm{B}$ ratio are therefore indications of appropriate prescribing. Antibiotics considered as broad spectrum were: combinations of penicillins (J01CR), second-generation and third-generation cephalosporins (J01DC, J01DD) and macrolides (J01F) (except erythromycin). Narrow-spectrum antibiotics were: $\beta$-lactam sensitive antibiotics (J01CE), first-generation cephalosporins (J01DB) and erythromycin (J01FA01).

\section{Statistical analysis}

Descriptive statistics were used to describe characteristics of children with or without asthma. The prevalence of antibiotic use was expressed as the number of users per 1000 person years (PY) to be interpreted as the number of children per 1000 who use antibiotics in 1 year. Antibiotic use was studied overall but also by type of antibiotic (ATC code pharmacological subgroup level). A Poisson regression model was applied to determine differences in antibiotic prescription rates. The effect of age, gender and calendar year was studied by means of a stratified analysis. Descriptive statistics were used to describe patient characteristics.

$\mathrm{X}^{2}$ tests or Fisher's exact test were used to examine differences in indication of use between children with asthma and children without asthma. CIs of proportions were derived using Wilson method for binomial proportions.

A $p$ value $<0.05$ was considered statistically significant. Jerboa, a custom-built software, was used to assess prevalence of antibiotic use and further analyses were conducted using SASV.9.4. ${ }^{20}$ 


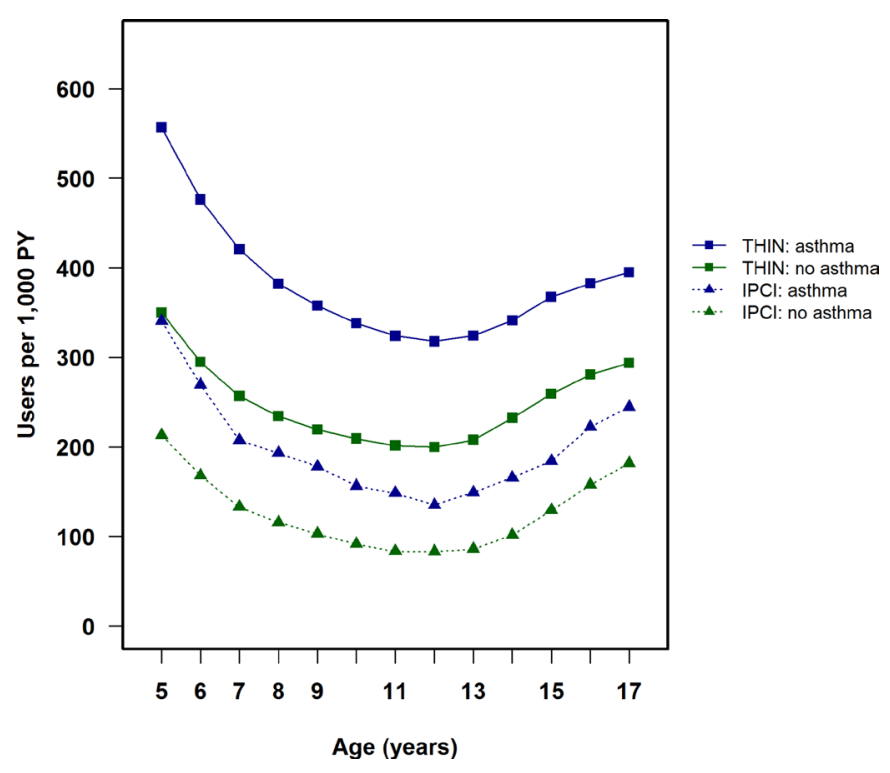

Figure 1 Age and asthma status-specific annual prevalence rate of antibiotic use. IPCI, Integrated Primary Care Information database; THIN, The Health Improvement Network; PY, person years.

\section{RESULTS}

The study population of IPCI consisted of 26750 children with asthma and 330916 children without asthma in total contributing to $946143 \mathrm{PY}$. The median age for children with asthma at start of follow-up was 10.8 years (IQR 6.4-14.6) and for children without asthma 10.3 years (IQR 6.1-13.9). The study population in THIN consisted of 152957 children with asthma and 1438097 children without asthma, in total contributing to 7241271 PY. Median age at start of follow-up was 7.9 years (IQR 5.0-11.4) for children with asthma and 6.0 years (IQR 5.0-10.2) for children without asthma.

During the study period, 186195 prescriptions of antibiotics were retrieved from the IPCI database and 3283887 from the THIN database. The overall annual prevalence of $\mathrm{AB}$ use in the entire paediatric population was 131/1000 PY for IPCI and twice as high, namely 263/1000 PY for THIN ( $<<0.001)$ (figure 1$)$. In both databases, children with asthma used significantly more antibiotics than children without asthma $(\mathrm{p}<0.0001)$. In IPCI, the prevalence rate ratio (PRR) of $\mathrm{AB}$ use in children with asthma versus use in non-asthmatic children was 1.65 (95\% CI 1.53 to 1.78 ) (adjusted for age, gender and calendar year). The same trend was observed in THIN with a PRR of 1.60 (95\% CI 1.54 to 1.66$)$. The number of $\mathrm{AB}$ prescriptions was higher than the number of users and children who used antibiotics received on average two antibiotic prescriptions per year. In both databases, the rate of antibiotic prescriptions decreased significantly with calendar time, both in children with or without asthma $(\mathrm{p}<0.05)$ (figure 2$)$.

In IPCI, $29 \%$ of the antibiotic prescriptions could not be linked to an indication of use on the day of prescription; this was $50 \%$ for THIN. Of those prescriptions with a known indication, the most common indication in all

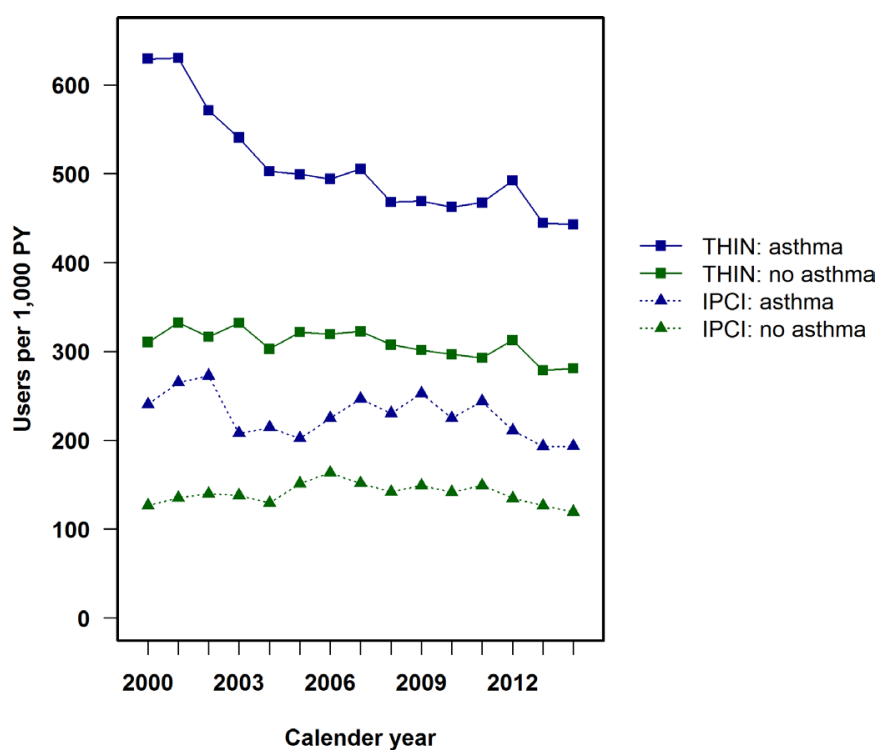

Figure 2 Annual prevalence rate of antibiotic use by calendar year. IPCI, Integrated Primary Care Information database; THIN, The Health Improvement Network; PY, person years.

children was URTI (41\% IPCI, 47\% THIN), followed by LRTIs with significantly higher proportions in children with asthma (18\% IPCI, 21\% THIN) than children without asthma (IPCI: 13\%, THIN: 12\%, p value for both databases $<0.001$ ) (figure 3). The most common LRTI for which $\mathrm{AB}$ were prescribed was acute bronchitis (figure 4).

In children with asthma, $14 \%$ (IPCI) to $4 \%$ (THIN) of antibiotics were prescribed for asthma exacerbation only. Compared with the THIN database, a smaller proportion of the prescriptions for asthmatics in IPCI were due to URTI, LRTI and skin infections, and a larger proportion in IPCI was due to UTI and asthma ( $p$ value for all indications $<0.001)$. Differences in prescriptions for non-asthmatic patients were mostly similar, except that in these cohorts more prescriptions were due to LRTI in IPCI than in THIN (13\% vs $12 \%$, p value $<0.001$ ).

The type of prescribed $\mathrm{AB}$ was different between databases (figures 5-6, table 1). In IPCI, the difference in type of antibiotic between children with and without asthma was most pronounced for macrolides $(22.1 \%$ of all AB prescriptions in children with asthma vs $15.9 \%$ in non-asthmatic children, $\mathrm{p}$ value $<0.0001)$. In THIN, this difference was less pronounced: macrolides were prescribed in $15.4 \%$ of prescriptions for children with asthma and $12.9 \%$ for children without asthma $(p<0.0001)$.

With regard to QIs, less appropriate antibiotic prescribing was observed for IPCI (Netherlands) compared with THIN (UK), with a higher $\mathrm{B} / \mathrm{N}$ ratio (IPCI: 3.4, THIN: 0.3, $\mathrm{p}<0.001$ ) and a lower $\mathrm{A} / \mathrm{B}$ ratio (IPCI: 1.1, THIN: 3.9, p<0.001) and AI (IPCI: 32.0, THIN: 36.1, $\mathrm{p}<0.001)$ in IPCI than in THIN. These findings remained when repeating the analysis for prescriptions for LRTI only. Overall, based on QIs, AB prescribing in children with asthma appeared less appropriate than in children without asthma (table 2). 
IPCI: asthma

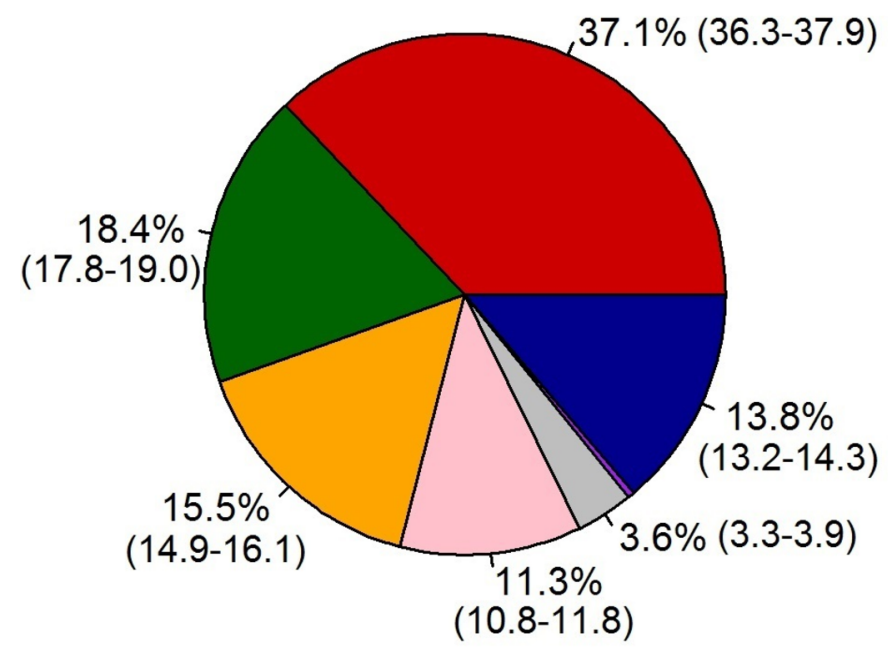

THIN: asthma

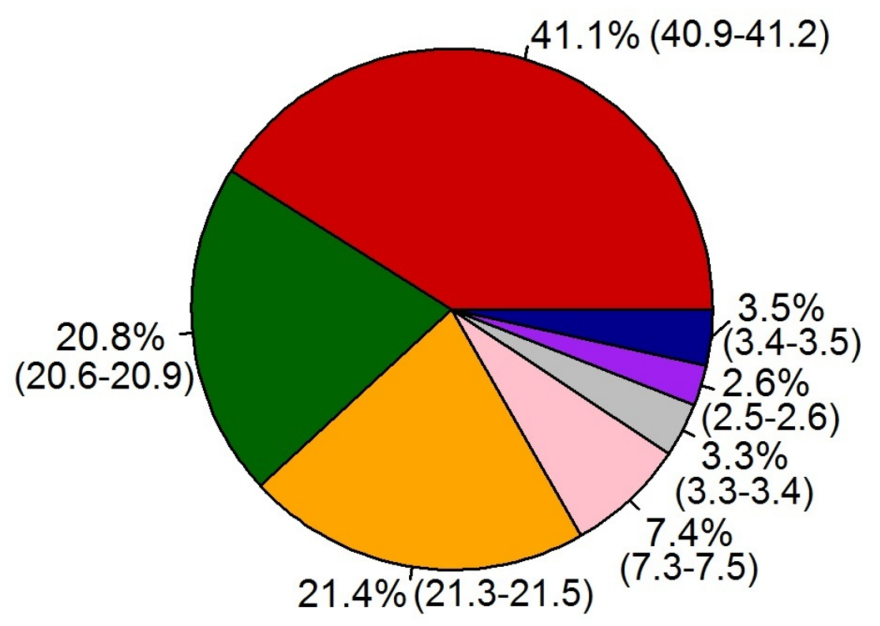

IPCI: no asthma

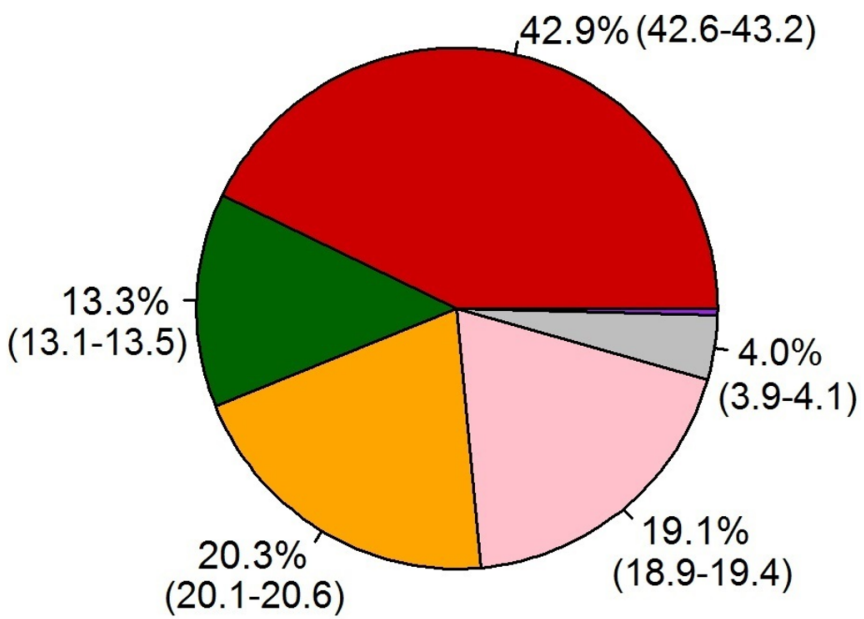

THIN: no asthma

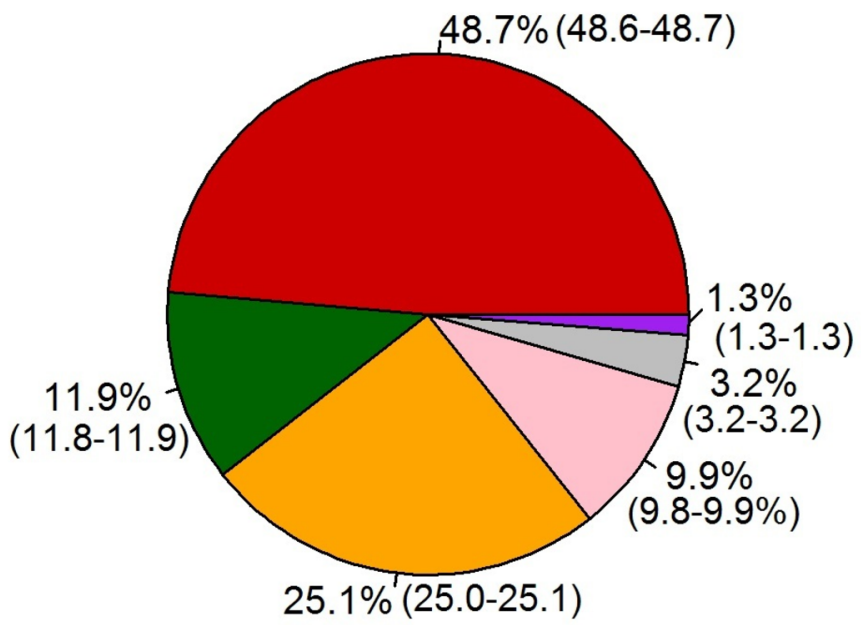

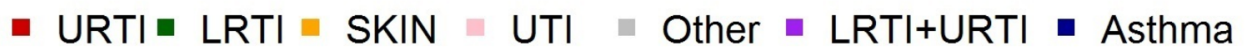

Figure 3 Indications of antibiotic use: proportion of known indications. IPCI, Integrated Primary Care Information database; LRTI, lower respiratory tract infection; SKIN, skin infection; THIN, The Health Improvement Network; URTI, upper respiratory tract infection; UTI, urinary tract infection.

The analyses of prescription rates, indications and QIs were repeated while stratifying for age and gender. After the age of 12, especially in girls, the number of prescriptions increased due to UTIs. Differences between children with and without asthma and between countries remained similar on stratification. Details on stratified analysis are available in online supplementary file 2.

\section{DISCUSSION}

In this international cohort study, we showed that children with asthma are more often prescribed antibiotics than children without asthma. This higher $\mathrm{AB}$ prescription rate in children with versus children without asthma was strikingly similar in the UK and the Netherlands, while overall use of $\mathrm{AB}$ prescriptions was substantially higher in the UK compared with the Netherlands. High use of $\mathrm{AB}$ in children with asthma was already reported in literature but, to our knowledge, we are the first who investigated indication of use. ${ }^{56}$

The indications of use were often bronchitis and asthma exacerbations, conditions for which antibiotics are in general not recommended. Indeed, according 


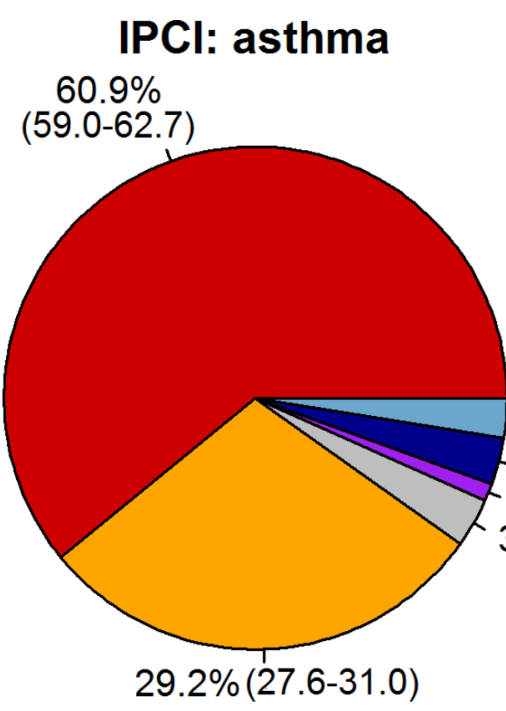

$2.5 \%(1.9-3.1)$

$3.0 \%(2.4-3.7)$

$1.1 \%(0.7-1.5)$

$3.2 \%(2.5-3.8)$
IPCI: no asthma

$66.8 \%$

$(66.1-67.6)$

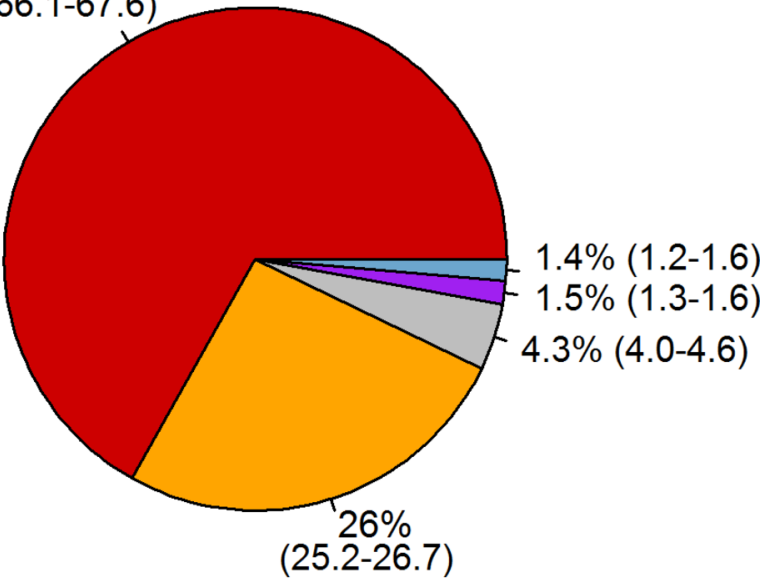

$(25.2-26.7)$
THIN: asthma

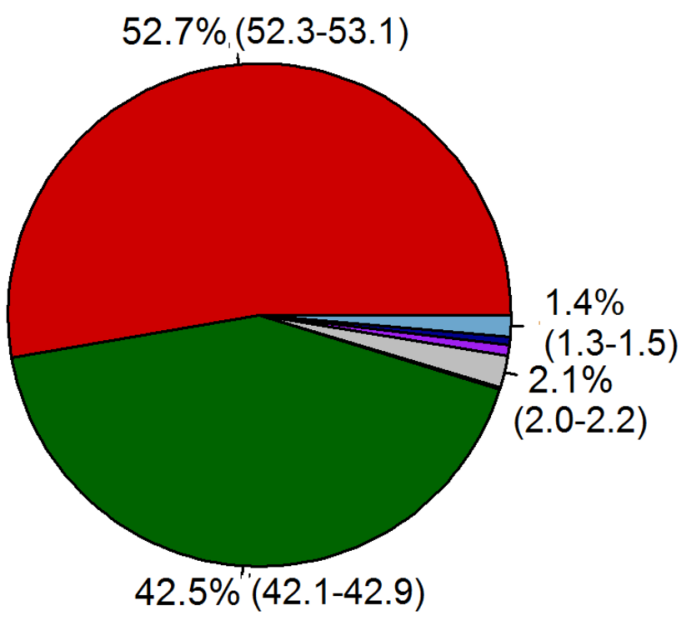

THIN: no asthma

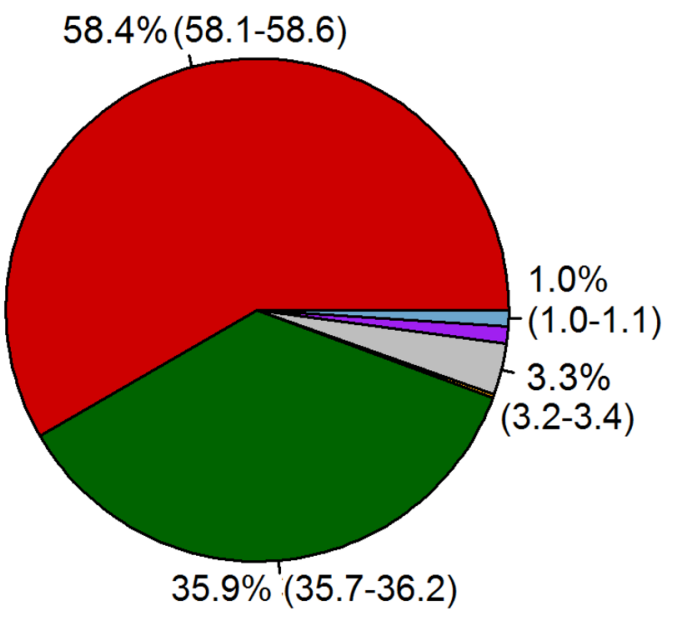

\begin{tabular}{|ll}
\hline Bronchitis & Pneumonia \\
- Unspecified & Influenza
\end{tabular}

Figure 4 Indications of lower respiratory tract infections. IPCI, Integrated Primary Care Information database; THIN, The Health Improvement Network.

to the guidelines of the Global Initiative of Asthma, use of $\mathrm{AB}$ for the treatment of asthma exacerbations is not recommended unless there is strong evidence of lung infection. ${ }^{7}$ Asthma is not a risk factor for complicated respiratory tract infections according to the British guidelines, and Dutch guidelines even emphasise that underlying asthma does not justify antibiotics in case of a LRTI. ${ }^{89}$ Additionally, it has been shown that asthma is not a risk factor for complications of influenza. ${ }^{21}$ One explanation for increased antibiotic prescribing for children with asthma could be that respiratory infectious syndromes in children with asthma present with various lower respiratory tract symptoms. This complicates the discrimination between a bacterial infection, a viral infection or an asthma exacerbation in primary care. Also, even though guidelines state that there is not enough evidence for treatment with antibiotics in case of an asthma exacerbation, it is being discussed that the supposedly anti-inflammatory effect of antibiotics (macrolides in particular) might be beneficial for patients with asthma. ${ }^{22-25}$ This might explain the relatively higher rate of macrolides prescriptions for asthmatic children in the Netherlands. However, the recommendation of macrolide use would only be beneficial for children with severe asthma whom are usually treated in secondary and tertiary care.

For the overall use of antibiotics in all children, it is remarkable that a large proportion was prescribed for URTIs. URTIs are notoriously caused by viruses for which 
Girls - asthma

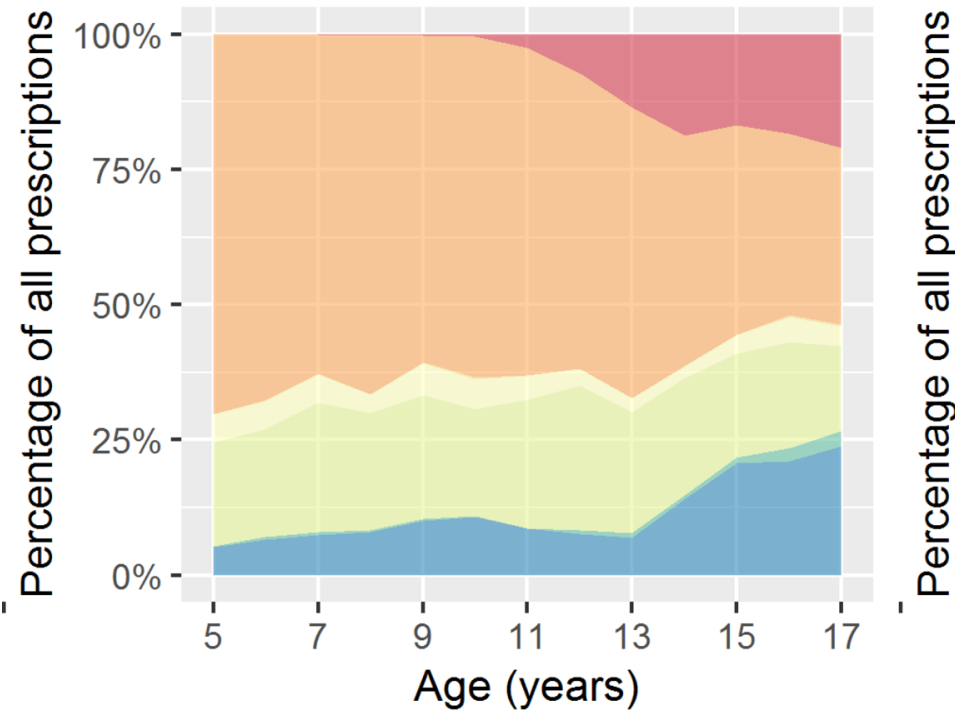

Boys - asthma

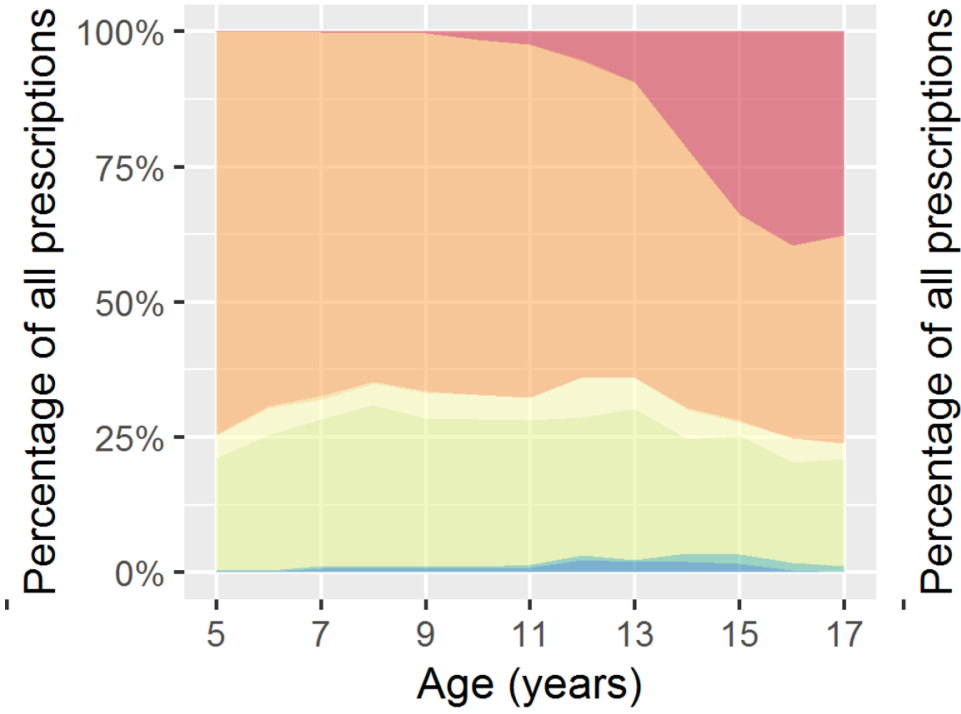

Girls - no asthma

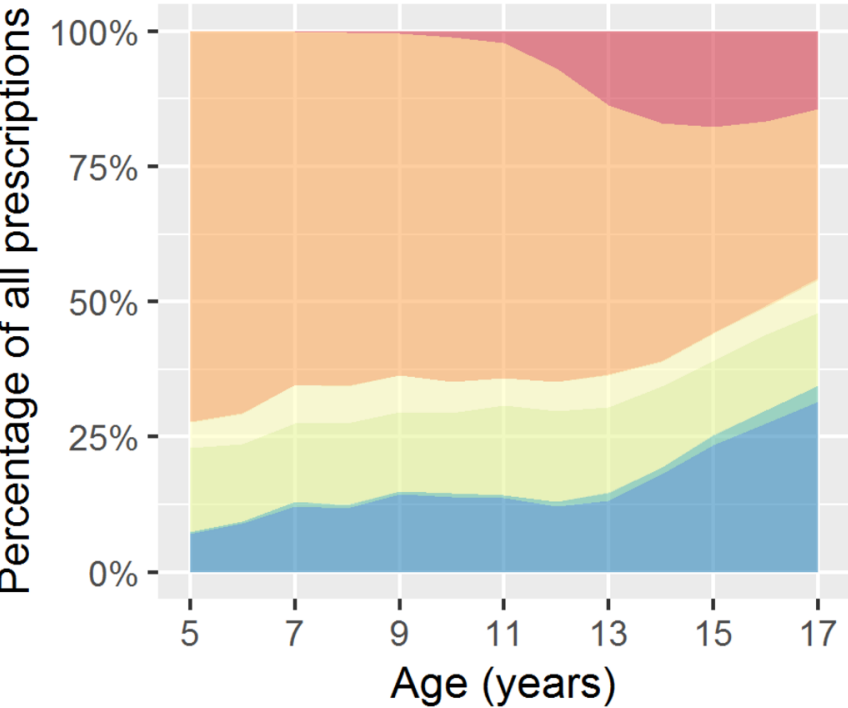

Boys - no asthma

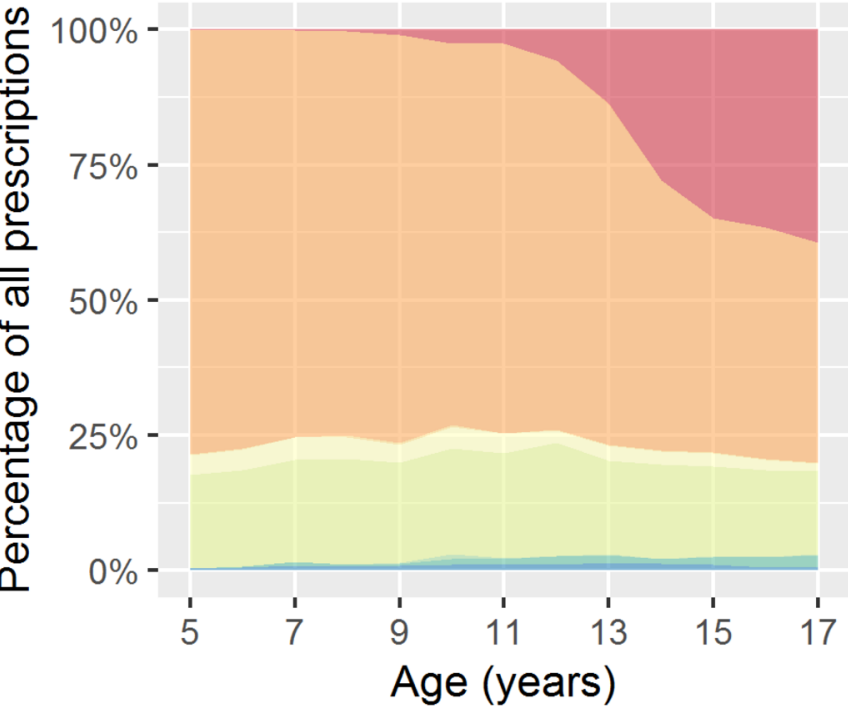

J01E (sulfonamides and trimethoprim) J01F (macrolides) 


\section{Girls - asthma}

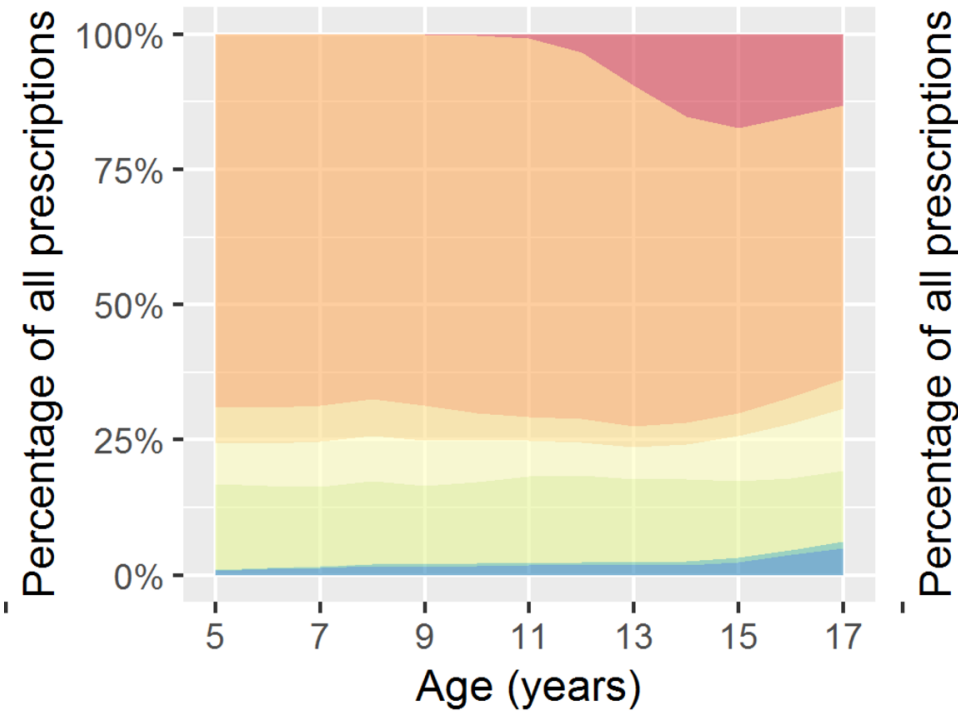

Boys - asthma
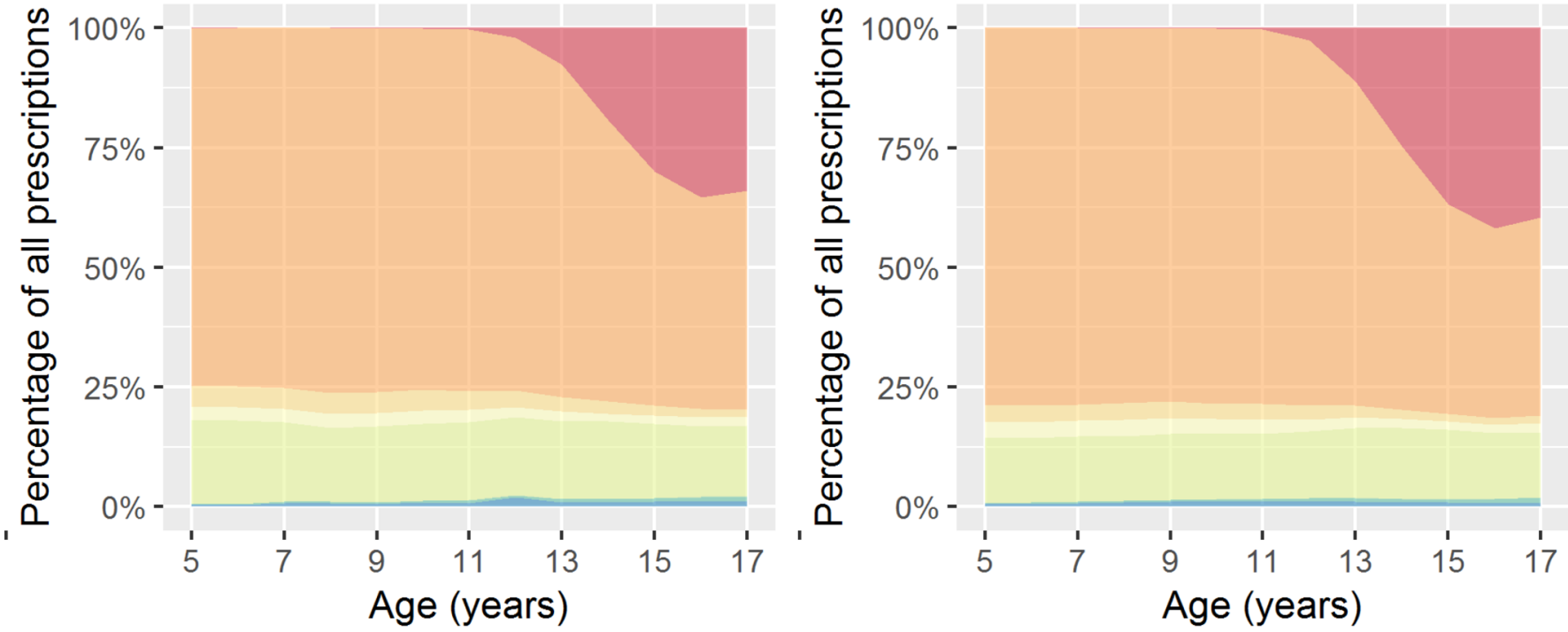

J01A (tetracyclines)

J01B (amphenicols)

\begin{abstract}
J01E (sulfonamides and trimethoprim) J01F (macrolides)
\end{abstract}

Girls - no asthma

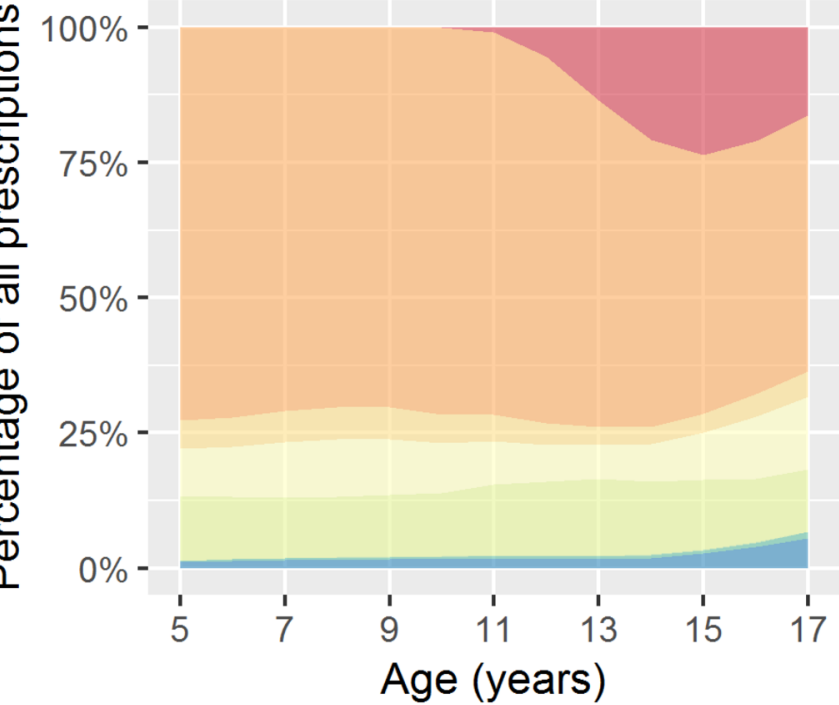

Boys - no asthma Age (years) J01X (Other) J01D (other B-lactam specific) were comparable. Although differences between asthmatics and non-asthmatics were statistically significant, compared with differences between countries they were almost negligible. Mainly country-specific differences in QIs were observed which was already reported in other studies. ${ }^{31}$ Although children in the UK receive twice as often antibiotics compared with Dutch children, the choice of antibiotics seems to be more appropriate in the UK. These country-specific differences in QIs might be explained by differences in availability of drugs, resistance patterns and national guidelines.

As for all observational research, this study has strengths and limitations: strengths of this study include the large number of patients that were followed over time and the fact that this is an international study. In addition, we present real life data, by using the electronic patient records of GP practices spread over the UK and the Netherlands. In both countries, the GP acts as a gatekeeper of the patient's medical care, minimising selection and information bias. Also, in contrast to other studies, we had information on all different indications of use, although not for all $\mathrm{AB}$ prescriptions. With regard to limitations, we might have under-reported pneumonia as indication of $A B$ use in THIN. In our study, pneumonia was defined based on pneumonia-specific Read codes. This classification was stricter than in other studies where the 


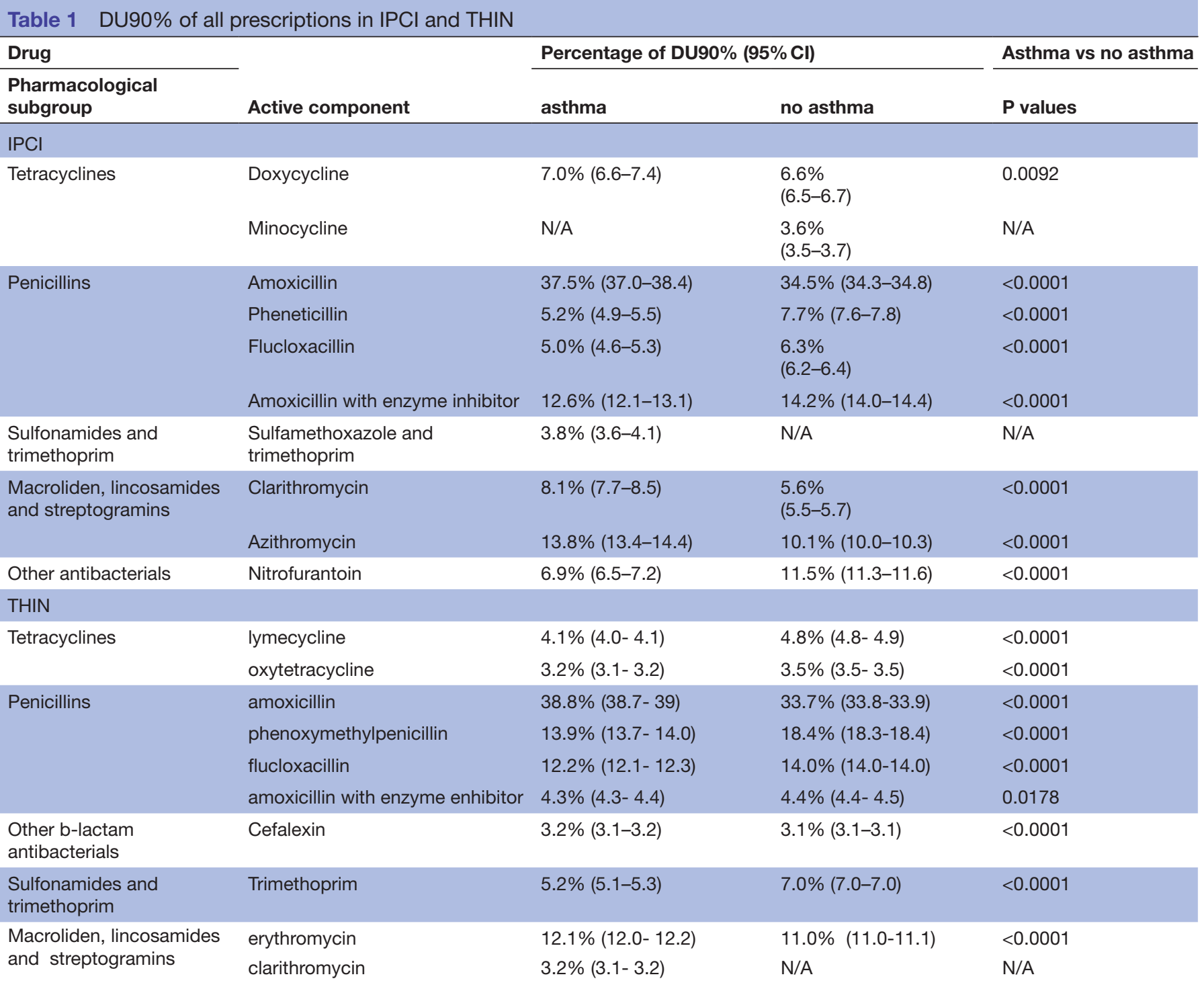

DU90\%, drug utilisation 90\%; IPCI, Integrated Primary Care Information database; N/A, not part of DU90\%; THIN, The Health Improvement Network.

Read code 'Acute lower respiratory infection (H062.00)' was also classified as 'pneumonia' while we classified that code as 'LRTI-unspecified'. ${ }^{32}$ For both databases, indications were based on diagnose codes without use of free text. The system automatically links a drug with the problem code it is prescribed within. In a busy consultation, all the prescriptions might be issued under one problem code. In the UK, performing an asthma review is part of the quality and outcomes framework which might lead to extra entries for asthma if a patient presents with another disease. For drugs with a single indication of use, this problem can be identified. In the IPCI and THIN databases, $98 \%$ and $94 \%$ of the minocycline prescriptions were linked to skin infections, respectively, and $98 \%$ and $96 \%$ of nitrofurantoin prescriptions were linked to UTIs, respectively. This suggests limited bias. Still, the bias might be more likely to occur in indications from the same system organ class-such as LRTI and asthma, but this can only be identified through free text validation.
Finally, misclassification of asthma could be a concern as asthma was based on the presence of asthma disease codes in combination of use of respiratory drugs: still the prevalence of asthma which we reported (IPCI 7.9\% and THIN 9.6\%) is in line with literature suggesting that asthma misclassification is minimal. ${ }^{33}$

To conclude, this study shows possibilities for further reduction and more sensible choice of antibiotic use, even in countries such as the Netherlands where antibiotic use is the lowest in the world. We showed that children with asthma are prescribed antibiotics often for self-limiting respiratory tract infections. Additionally, asthma treatment in primary care can be optimised by following (inter)national guidelines more strictly in terms of prescription rates and type of drugs. This can be done by raising awareness among GPs, patients and their parents. Additionally, careful implementation of point-of care tests such as CRP testing and procalcitonin-guided management in guidelines will help in reducing antibiotic 
therapy rates. Further awareness can reduce unnecessary antibiotic use and limit antibiotic resistance.

Author affiliations

${ }^{1}$ Department of Medical Informatics, Erasmus University, Rotterdam, The Netherlands

2Department of Pediatric Pulmonology, Erasmus University/Sophia Children's Hospital, Rotterdam, The Netherlands

${ }^{3}$ Department of Bioanalysis, Pharmaceutical Care Unit, Faculty of Pharmaceutical Sciences, Ghent University, Ghent, Belgium

${ }^{4}$ Department of General Practice, Erasmus University, Rotterdam, The Netherlands

${ }^{5}$ Julius Global Health, University Medical Centre Utrecht, Utrecht, The Netherlands

${ }^{6}$ Department of Infection Control and Epidemiology, OLV Hospital, Aalst, Belgium

Contributors EJB, TK, HMJ and KV contributed to the conception and design, acquisition of data and analyses and interpretation of the data, drafted the article, revised it critically for important intellectual content and gave final approval of the version to be published. PJEB, JCdJ and MCJMS contributed to the conception and design and acquisition of data, interpretation of the data, revised the drafted manuscript critically for important intellectual content and gave final approval of the version to be published.

Funding The authors have not declared a specific grant for this research from any funding agency in the public, commercial or not-for-profit sectors.

Competing interests None declared.

Patient consent Not required.

Ethics approval The scientific review committee of IPCl and THIN approved this study (nr. 07/2016 and 16THIN046)

Provenance and peer review Not commissioned; externally peer reviewed.

Data sharing statement Statistical codes are available on request from the corresponding author.

Open access This is an open access article distributed in accordance with the Creative Commons Attribution Non Commercial (CC BY-NC 4.0) license, which permits others to distribute, remix, adapt, build upon this work non-commercially, and license their derivative works on different terms, provided the original work is properly cited, appropriate credit is given, any changes made indicated, and the use is non-commercial. See: http://creativecommons.org/licenses/by-nc/4.0/.

\section{REFERENCES}

1. World Health Organization,. Antimicrobial resistance - fact sheet. 2017 http://www.who.int/mediacentre/factsheets/

2. World Health Organization,. Global action plan on antimicrobial resistance. $2015 \mathrm{http}: / / \mathrm{www}$.who.int/

3. Kinoshita T, Tokumasu H, Tanaka S, et al. Policy implementation for methicillin-resistant Staphylococcus aureus in seven European countries: a comparative analysis from 1999 to 2015. J Mark Access Health Policy 2017;5:1351293.

4. Goossens H, Ferech M, Vander Stichele R, et al. Outpatient antibiotic use in Europe and association with resistance: a cross-national database study. Lancet 2005;365:579-87.

5. De Boeck K, Vermeulen F, Meyts I, et al. Coprescription of antibiotics and asthma drugs in children. Pediatrics 2011;127:1022-6.

6. Stallworth LE, Fick DM, Ownby DR, et al. Antibiotic use in children who have asthma: results of retrospective database analysis. $J$ Manag Care Pharm 2005;11:657-62.

7. Global initiative for Asthma. 2017 GINA Report, Global Strategy for Asthma Management and Prevention. 2017 http://ginasthma.org/ gina-reports/

8. Verlee L, Verheij TJ, Hopstaken RM, et al. [Summary of NHG practice guideline 'Acute cough']. Ned Tijdschr Geneeskd 2012;156:A4188.

9. National Institute for Health and Clinical Excellence. Antibiotic prescribing: prescribing of antibiotics for self-limiting respiratory tract infections in adults and children in primary care. London: NICE guideline CG69, 2008.

10. Tacconelli E, De Angelis G, Cataldo MA, et al. Does antibiotic exposure increase the risk of methicillin-resistant Staphylococcus aureus (MRSA) isolation? A systematic review and meta-analysis. $J$ Antimicrob Chemother 2008:61:26-38.

11. Vlug AE, van der Lei J, Mosseveld BM, et al. Postmarketing surveillance based on electronic patient records: the IPCI project. Methods Inf Med 1999;38(4-5):339-44. 
12. Lewis JD, Schinnar R, Bilker WB, et al. Validation studies of the health improvement network (THIN) database for pharmacoepidemiology research. Pharmacoepidemiol Drug Saf 2007:16:393-401.

13. Blak BT, Thompson M, Dattani H, et al. Generalisability of The Health Improvement Network (THIN) database: demographics, chronic disease prevalence and mortality rates. Inform Prim Care 2011;19:251-5.

14. Coenen S, Ferech M, Haaijer-Ruskamp FM, et al. European Surveillance of Antimicrobial Consumption (ESAC): quality indicators for outpatient antibiotic use in Europe. Qual Saf Health Care 2007; $16: 440-5$

15. Wettermark B, Pehrsson A, Jinnerot D, et al. Drug utilisation $90 \%$ profiles-a useful tool for quality assessment of prescribing in primary health care in Stockholm. Pharmacoepidemiol Drug Saf 2003;12:499-510.

16. Porta A, Hsia Y, Doerholt $\mathrm{K}$, et al. Comparing neonatal and paediatric antibiotic prescribing between hospitals: a new algorithm to help international benchmarking. J Antimicrob Chemother 2012;67:1278-86.

17. Bergman U, Popa C, Tomson Y, et al. Drug utilization $90 \%$-a simple method for assessing the quality of drug prescribing. Eur $J$ Clin Pharmacol 1998;54:113-8.

18. Saleh EA, Schroeder DR, Hanson AC, et al. Guideline-concordant antibiotic prescribing for pediatric outpatients with otitis media, community-acquired pneumonia, and skin and soft tissue infections in a large multispecialty healthcare system. Clin Res Infect Dis 2015;2.

19. Bowen SJ, Thomson AH. British thoracic society paediatric pneumonia audit: a review of 3 years of data. Thorax 2013;68:682-3.

20. Trifirò G, Coloma PM, Rijnbeek PR, et al. Combining multiple healthcare databases for postmarketing drug and vaccine safety surveillance: why and how? J Intern Med 2014;275:551-61.

21. Gill PJ, Ashdown HF, Wang K, et al. Identification of children at risk of influenza-related complications in primary and ambulatory care: a systematic review and meta-analysis. Lancet Respir Med 2015;3:139-49.
22. Kew KM, Undela K, Kotortsi I, et al. Macrolides for chronic asthma. Cochrane Database Syst Rev 2015;9:CD002997.

23. Joks R, Durkin HG. Non-antibiotic properties of tetracyclines as antiallergy and asthma drugs. Pharmacol Res 2011;64:602-9.

24. Johnston SL, Szigeti M, Cross M, et al. Azithromycin for acute exacerbations of asthma : the azalea randomized clinical trial. JAMA Intern Med 2016;176:1630-7.

25. Gibson PG, Yang IA, Upham JW, et al. Effect of azithromycin on asthma exacerbations and quality of life in adults with persistent uncontrolled asthma (AMAZES): a randomised, double-blind, placebo-controlled trial. Lancet 2017;390:659-68.

26. Tonkin-Crine SK, Tan PS, van Hecke O, et al. Clinician-targeted interventions to influence antibiotic prescribing behaviour for acute respiratory infections in primary care: an overview of systematic reviews. Cochrane Database Syst Rev 2017;9:CD012252.

27. Spurling GK, Del Mar CB, Dooley L, et al. Delayed antibiotic prescriptions for respiratory infections. Cochrane Database Syst Rev 2017;9:CD004417.

28. Touboul-Lundgren $\mathrm{P}$, Jensen $\mathrm{S}$, Drai J, et al. Identification of cultural determinants of antibiotic use cited in primary care in Europe: a mixed research synthesis study of integrated design "Culture is all around us". BMC Public Health 2015;15:908.

29. Hulscher ME, van der Meer JW, Grol RP. Antibiotic use: how to improve it? Int J Med Microbiol 2010;300:351-6.

30. Vodicka TA, Thompson M, Lucas P, et al. Reducing antibiotic prescribing for children with respiratory tract infections in primary care: a systematic review. Br J Gen Pract 2013;63:e445-e454.

31. de Bie S, Kaguelidou F, Verhamme KM, et al. Using prescription patterns in primary care to derive new quality indicators for childhood community antibiotic prescribing. Pediatr Infect Dis $J$ 2016;35:1317-23.

32. Myles PR, McKeever TM, Pogson Z, et al. The incidence of pneumonia using data from a computerized general practice database. Epidemiol Infect 2009;137:709-16.

33. (ISAAC). Worldwide variations in the prevalence of asthma symptoms: the International Study of Asthma and Allergies in Childhood (ISAAC). Eur Respir J 1998;12:315-35. 